\title{
BADE, Klaus J., Europa in Bewegung. Migration vom späten 18. Jahrhundert bis zur Gegenwart
}

\section{Karine Rance}

\section{OpenEdition}

\section{Journals}

Édition électronique

URL : http://journals.openedition.org/ifha/1213

DOI : 10.4000/ifha.1213

ISSN : 2198-8943

Éditeur

IFRA - Institut franco-allemand (sciences historiques et sociales)

Référence électronique

Karine Rance, «BADE, Klaus J., Europa in Bewegung. Migration vom späten 18. Jahrhundert bis zur Gegenwart », Revue de l'IFHA [En ligne], Date de recension, mis en ligne le 01 janvier 2002, consulté le 22 septembre 2020. URL : http://journals.openedition.org/ifha/1213 ; DOI : https://doi.org/10.4000/ ifha. 1213

Ce document a été généré automatiquement le 22 septembre 2020.

(C)IFHA 


\title{
BADE, Klaus J., Europa in Bewegung. Migration vom späten 18. Jahrhundert bis zur Gegenwart
}

\author{
Karine Rance
}

1 La collection Europa Bauen de l'éditeur munichois propose une approche thématique de l'histoire européenne en faisant appel chaque fois à des spécialistes. K.B., directeur de l'Institut für Migrationsforschung und Interkulturelle Studien (IMIS) de l'université d'Osnabrück, devait tout naturellement trouver place dans cette collection. Il poursuit dans ce volume son enquête sur les migrations européennes en mettant ses talents de narrateur au service d'une approche macro-historique des mouvements de populations européennes de la fin du XVIIIe s. jusqu'à nos jours.

K.B., évoquant un homo migrans, rappelle que l'Europe est en perpétuel mouvement depuis l'Ancien Régime et présente un panorama, ancré dans les réalités sociales, politiques, économiques, des mobiles et des formes de migrations. Les grandes tendances sont toujours illustrées par des exemples précis pris dans les différents pays européens. L'ouvrage se présente en cinq parties : fin de l'Ancien Régime, 1800-1914, 1914-1945, guerre froide, fin du XXe s. L'approche est double : K.B. s'intéresse d'une part aux facteurs d'émigration, non pas individuels (il récuse explicitement une approche en termes de trajectoires individuelles ou familiales) mais structurels tels que le processus différencié d'industrialisation, l'explosion démographique, l'impérialisme, le nationalisme, les guerres, le nazisme, la décolonisation ou l'effondrement des pays communistes. K.B. reprend dans cette optique les classifications qui différencient les migrations de survie, les migrations visant à une promotion professionnelle, les migrations politiques, etc. D'autre part, K.B. considère les politiques menées à l'égard des migrants. Il questionne l'évolution du statut de l'étranger et la catégorie du réfugié politique au regard des mesures prises par les gouvernements européens. Il balaie ainsi les multiples formes de mouvements de populations aux XIXe et XXe s., depuis les départs pour les colonies jusqu'à la déportation par les nazis, en passant par les transferts de technologie, l'espionnage industriel ou les migrations saisonnières. 
L'aspect le plus intéressant de cette très riche étude réside sans doute dans l'évolution du contrôle des migrants par l'État moderne. Le souci de contrôler les migrations paraît toutefois sous-estimé par l'auteur avant 1815 (voir la recension de l'ouvrage de Th. Höpel dans le présent Bulletin), mais cela tient sans doute au fait que seules les migrations professionnelles sont prises en compte dans le survol qui est fait des mouvements de populations sous l'Ancien Régime. D'une indéniable actualité, cette synthèse trace un pan d'une histoire européenne à poursuivre.

3 Karine RANCE 